\title{
Design and Simulation of Proton Exchange Membrane Fuel Cell Exhaust Gas Recovery System
}

\author{
Long $\mathrm{Li}^{1}$, QianChao Liang ${ }^{1}$, JianFeng Zhao ${ }^{1}$, Yang Zhang ${ }^{1}$, YiFan Liang ${ }^{1, *}$ \\ ${ }^{1}$ College of Power Engineering, Naval University of Engineering, Wuhan, Hubei, China
}

\begin{abstract}
The compressed air from high-pressure compressor enters the proton exchange fuel cell and was discharged from the cathode after reacting. This part of the exhaust gas had a certain residual pressure. In order to study the effect of cathode exhaust gas residual pressure recovery on the efficiency of proton exchange membrane fuel cell system, this paper used Simulink software to establish a proton exchange membrane fuel cell exhaust gas recovery system model. In the model, the mass flow of supply air was controlled by controlling the air excess ratio $\lambda_{\text {air }}$. Under this condition, the work done by the exhaust gas on the turbine could account for $18 \%$ of the parasitic power consumption. The simulation results showed that this system could increase the system power by up to $13 \%$ compared with the energy recovery turbine system, which had good consistency, which was of great significance for PEMFC system design and exhaust gas recovery.
\end{abstract}

\section{Introduction}

Proton Exchange Membrane Fuel Cell (PEMFC) had some advantages, such as fast start-up, low operating temperature and low noise. So the research of PEMFC system had received worldwide attention. The air supply of the PEMFC was usually compressed by a compressor, cooled by cooling system, dampened by humidifying system, and sent to the cathode of the fuel cell stack, and then discharged after being reacted inside the battery. In this process, there was large parasitic power consumption, which was a crucial factor affecting the efficiency of the PEMFC system. The gas discharged after the reaction also had a certain temperature and a part of the pressure energy. The recovery of this part of exhaust gas was an important measure to improve the efficiency of the PEMFC system. Therefore, it was necessary to explore the factors affecting the efficiency of the PEMFC system by designing the PEMFC exhaust gas recovery system. The recovered energy in the form of shaft power could be utilized to drive an air compressor by means of combination with an electric motor [1]. Another way to make use of the recovered power is to introduce a turbocharger into the fuel cell system's air sub-system, connecting its pipe with the electric compressor in parallel or in series [2]. There already had been some research on the modeling the PEMFC system, which was helpful to the work of this paper.

Reference [3,4] established a air supply system model of PEMFC and gave an optimal control method about air excess ratio. Reference [5] designed a load governor which could be added to the air supply control system to monitor the load and prevent violation of constraints by modifying the load command to the fuel cell system. Reference [6] built a PEMFC system that employed a turbocharger to reuse the waste energy. Reference [7] gave two methods to combine the turbocharger with an electric compressor, namely in series and in parallel, which were evaluated for a fuel cell system.

In this paper, the air supply system of PEMFC was built by controlling the air excess ratio. Based on this model, a turbine system was built according to the turbine MAP diagram[3] to recover the energy from the exhaust gas. Second a model of the series supercharger composite supercharging mathematical model was first built to reduce the parasitic power consumption of compressor and improve the power of system.

\section{PEMFC exhaust gas recovery system model}

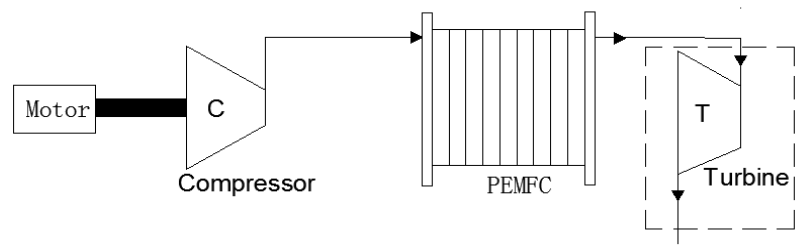

Fig. 1. PEMFC exhaust gas recovery system.

In the Fig.1, there was a air supply system (motor and compressor), a PEMFC stack, a turbine. In this paper, the cooling module and Humidifying module were ignored(supposed the temperature of the compressed air from the compressor could be cooled to the stack

*Corresponding author: YFanLiang@yeah.net 
operating temperature and the humidification rate of compressed air could reach $100 \%$ ).

\subsection{PEMFC stack model}

The fuel cell's polarization curve is often described by [8]:

$$
V_{\text {cell }}=E_{\text {Nerst }}-V_{\text {act }}-V_{\text {ohm }}-V_{\text {con }}
$$

where $V_{\text {cell }}$ is the output voltage of the single cell, $E_{\text {Nerst }}$ is the thermodynamic potential, $V_{\text {act }}$ is activation losses, $V_{\text {ohm }}$ is ohmic losses, $V_{\text {con }}$ is concentration losses.

According to reference $[9,10]$, the formula of the thermodynamic potential can be expressed as:

$$
\begin{gathered}
E_{\text {Nerst }}=1.229-8.5 \times 10^{-4} \times(\mathrm{T}-298.15)+ \\
4.308 \times 10^{-5} \mathrm{~T} \times\left(\ln P_{\mathrm{H}_{2}}+0.5 \ln P_{\mathrm{O}_{2}}\right)
\end{gathered}
$$

where $\mathrm{T}$ is the working temperature of the stack, $P_{H_{2}}$ is effective partial pressure of hydrogen, $P_{\mathrm{O}_{2}}$ is effective partial pressure of oxygen.

Ohmic losses consist of two parts of impedance, according to Ohm's law, the formula is:

$$
V_{\text {ohm }}=I R_{\text {int }}=I\left(R_{M}+R_{C}\right)
$$

where $R_{M}$ is equivalent membrane impedance, $R_{C}$ is the impedance that prevents protons from passing through the proton membrane.

According to the suggestion given in reference[10], concentration losses can be expressed as:

$$
V_{\text {con }}=\operatorname{mexp}(-n I / A)
$$

where $m$ and $n$ are are quality transfer control factors that are determined by the working state of the PEMFC.

\subsection{Air supply system}

\subsubsection{Compressor model}

The compressor model was built based on the rotational parameter model and the characteristic curve of the compressor. The rotational parameter model can describe the dynamic characteristics of compressor speed $[3,4]$.

$$
J_{c p} \frac{d \omega_{c p}}{d t}=\tau_{c m}-\tau_{c p}
$$

where $J_{c p}$ is the compressor inertia, $\omega_{c p}$ is the rotational speed of compressor, $\tau_{c m}$ is the motor driving torque of compressor, $\tau_{c p}$ is the load torque of compressor.

$$
n_{c}=\frac{\omega_{c p} \cdot 60}{2 \times 3.14}
$$

where $n_{c}$ is the compressor speed.

The compressor model of this paper was built based on the experimental data provided in reference[3,4]. In order to reflect the change of compressor inlet conditions accurately, this paper describes the working state of compressor with corrected flow and corrected speed.

$$
\pi=f_{1}\left(G_{\text {in }} \frac{P_{0} \sqrt{T_{\text {in }}}}{P_{\text {in }} \sqrt{T_{0}}}, n_{c} \frac{\sqrt{T_{0}}}{\sqrt{T_{\text {in }}}}\right)
$$

where $\pi$ is the pressure ratio, $G_{\text {in }}$ is inlet flow, $P_{\text {in }}$ is inlet pressure, $T_{i n}$ is inlet temperature, $P_{0}=1 \mathrm{~atm}$, $T_{0}=298.15 \mathrm{~K}$

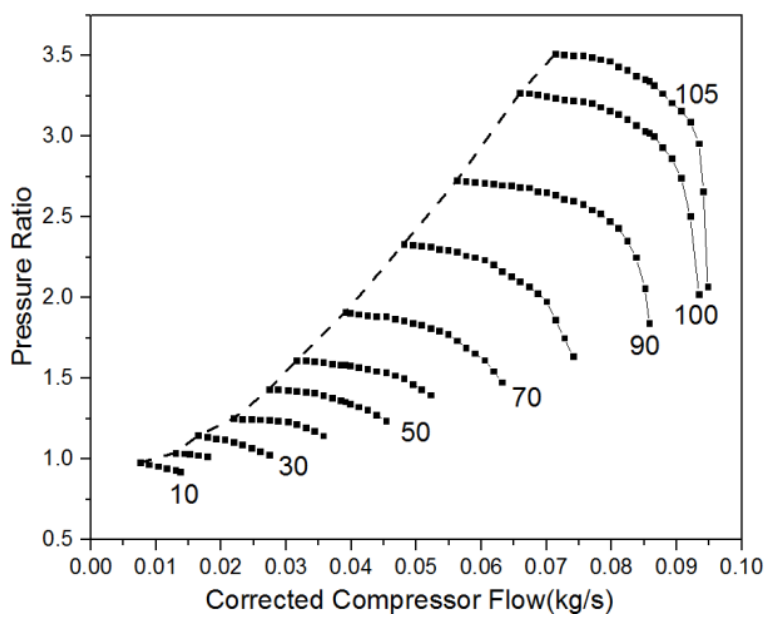

Fig. 2. $\pi-G^{\prime}$ Characteristic Curve

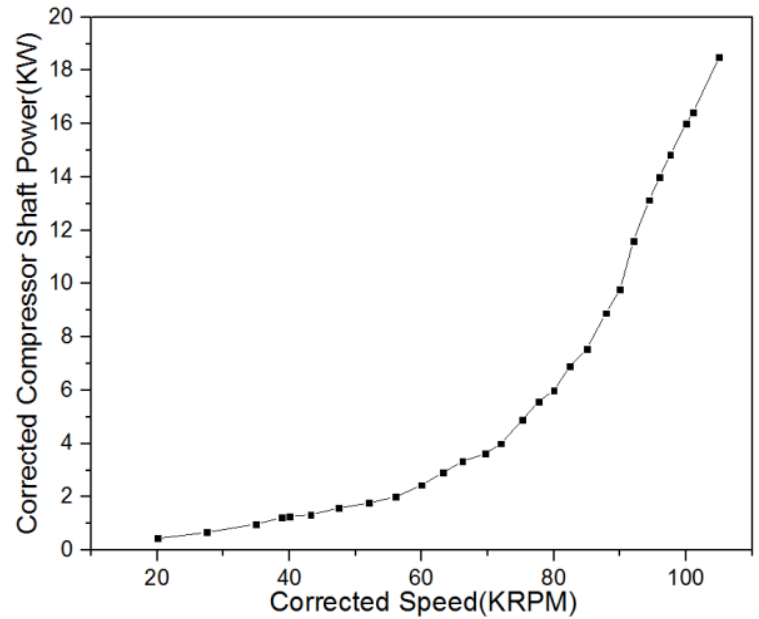

Fig. 3. $\mathrm{P}-n^{\prime}$ Characteristic Curve

According to the data of Fig.2, the compressor mass flow model can be built by using the Look-up table module in Simulink software. The formula of corrected flow can be obtained by combining Eq. (1-7) 


$$
F_{c r}=f_{2}\left(\pi, n_{c r}\right)
$$

where $n_{c r}$ is corrected speed.

The parasitic power consumption of compressor $W_{C}$ expressed as:

$$
W_{C}=F_{c p} C_{p a} T_{1}\left(\pi^{m_{a}}-1\right) / \eta_{c}
$$

where $F_{c p}$ is the flow of compressor, $c_{p a}$ is air specific heat capacity at constant pressure, $\eta_{c}$ is the efficiency of compressor.

\subsubsection{Manifold model}

The cathode supply manifold aggregates all the pipe and interface volumes connected between the compressor outlet and the PEMFC cathode. So the cathode supply manifold model can be established according to the law of mass conservation.

$$
\frac{\mathrm{d} m_{s m}}{d t}=F_{c p}-F_{s m, o u t}
$$

where $F_{c p}$ is the mass flow rate of the compressor entering the supply manifold, $F_{s m, o u t}$ is the mass flow out of the supply manifold, $m_{s m}$ is the mass of gas accumulated in the supply manifold.

\subsubsection{Turbine model}

The Look-up table module was used to establish the turbine model according to the working characteristic curve of the turbine. According to the experimental data in reference [11], the turbine model is established:

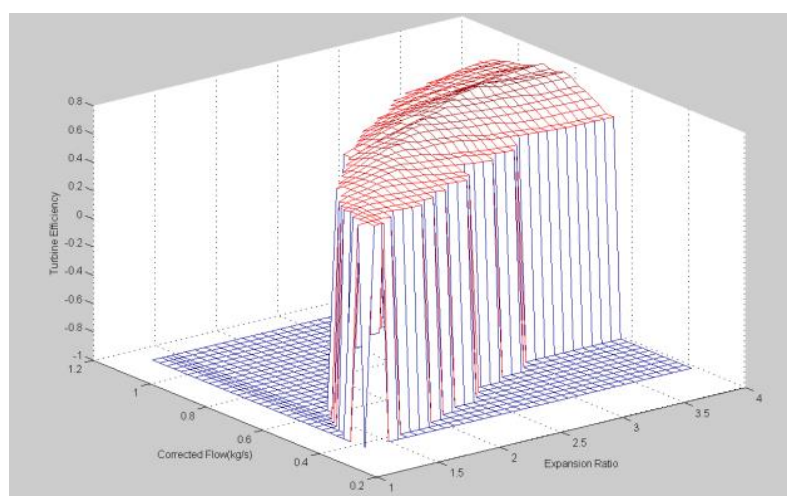

Fig. 4. Mathematical model of turbine

turbine expansion ratio is:

$$
\mu=f_{3}\left(\frac{G_{i n, t} \sqrt{T_{i n, t}}}{P_{i n, t}}, \frac{n_{T}}{\sqrt{T_{i n, t}}}\right)
$$

turbine characteristic efficiency is:

$$
\eta_{T}=f_{4}\left(\frac{G_{i n, t} \sqrt{T_{i n, t}}}{P_{i n, t}}, \frac{n_{T}}{\sqrt{T_{i n, t}}}\right)
$$

where $G_{i n, t}$ is the inlet mass flow of turbine, $T_{i n, t}$ is the inlet temperature of turbine, $P_{i n, t}$ is the inlet pressure of turbine, $n_{T}$ is the speed of turbine.

\subsection{Cathode air dynamic pressure model}

The turbine mainly recovers the pressure energy of exhaust gas, so it is very necessary to establish the dynamic model of PEMFC cathode air pressure. According to the law of conservation of mass, the following formulas can be obtained:

$$
\frac{d m_{O_{2}}}{d t}=F_{O_{2, \text { in }}}-F_{O_{2, \text { out }}}-F_{O_{2, \text { rec }}}
$$

$$
\frac{d m_{N_{2}}}{d t}=F_{N_{2, \text { in }}}-F_{N_{2, \text { out }}}
$$

where $m_{\mathrm{O}_{2}}$ is the mass of oxygen, $m_{N_{2}}$ is the mass of nitrogen, $F_{O_{2, \text { in }}}$ is the inflow mass flow of oxygen, $F_{N_{2, \text { in }}}$ is the inflow mass flow of nitrogen, $F_{O_{2, \text { out }}}$ is outflow mass flow of oxygen, $F_{N_{2, \text { out }}}$ is the outflow mass flow of nitrogen, $F_{O_{2, r e c}}$ is the mass flow of oxygen consumed by participating in the reaction.

\subsection{System power consumption model}

In the proton exchange membrane fuel cell exhaust gas recovery system, PEMFC will produce electric energy after chemical reaction, the compressor consumes a portion of energy (also known as parasitic power consumption) when supplying air to the PEMFC cathode and the recovery of cathode exhaust gas from the PEMFC by turbine will produce a part of the energy. (suppose the power consumed by the cooler and humidifier is about $2 \mathrm{KW}$ ), so the system power consumption is:

$$
W_{\text {sys }}=W_{\text {sta }}-W_{C}+W_{t u r}-W_{\text {other }}
$$

where $W_{\text {sys }}$ is the power of system, $W_{\text {other }}$ is the power consumed by the cooler and humidifier, $W_{\text {sta }}$ is the power of PEMFC.

\section{Analysis of simulation results}

When the air excess ratio is large, the parasitic power consumption of the compressor will increase, which will lead to the decrease of the system efficiency. When the air excess ratio is too small, the lack of oxygen required for PEMFC reaction will cause damage to the stack life and the efficiency of PEMFC will be reduced. Therefore, 
according to the change of external load current, the air excess ratio $\lambda_{\text {air }}$ will be controlled so as to control the flow rate of compressor to optimize the power of the system. According to the reference [3], when $\lambda_{\text {air }}=2 \sim 2.4$, the system efficiency will be optimal. Therefore, $\lambda_{\text {air }}$ is controlled to about 2 in this paper.

$$
\lambda_{\text {air }}=\frac{4 F \cdot F_{c p}}{N I M_{\text {air }}}
$$

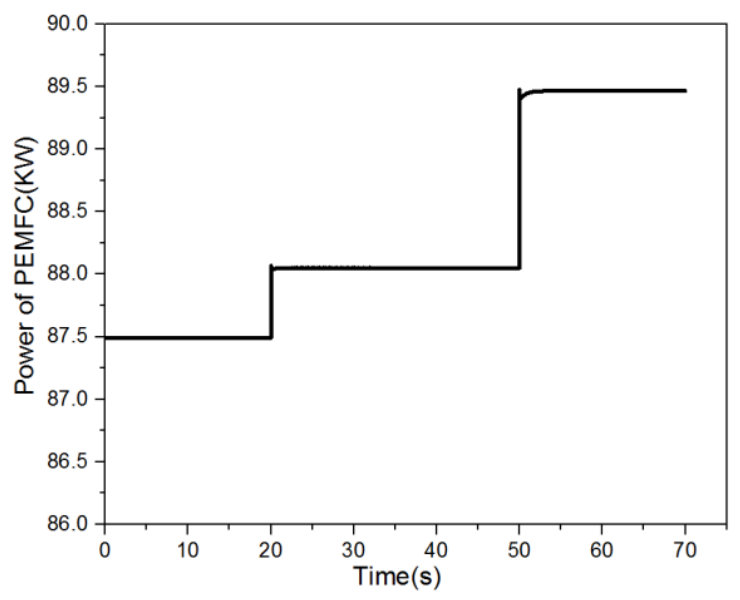

Fig. 5. Power of PEMFC stack

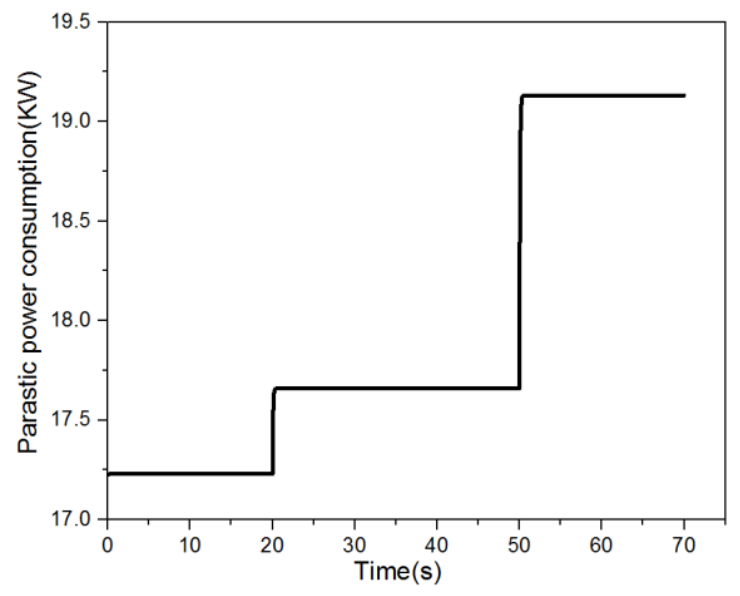

Fig. 6. Parasitic power consumption of compressor

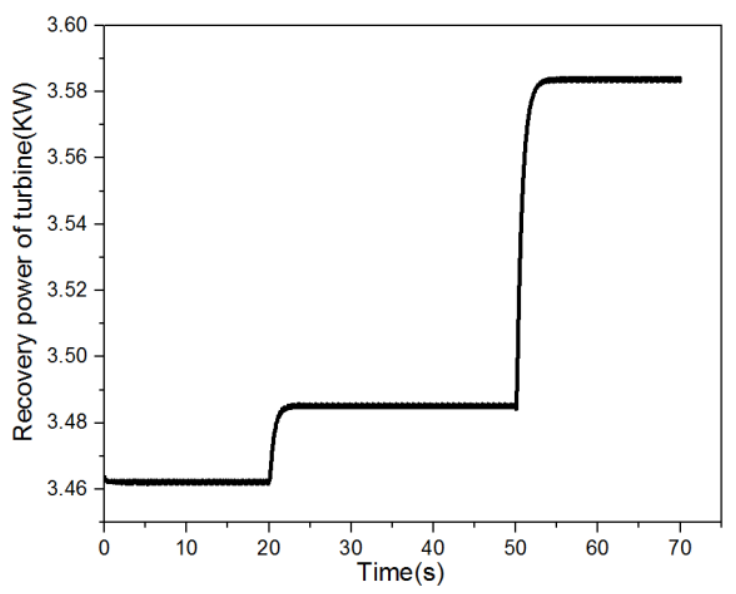

Fig. 7. The power done by exhaust gases on turbine

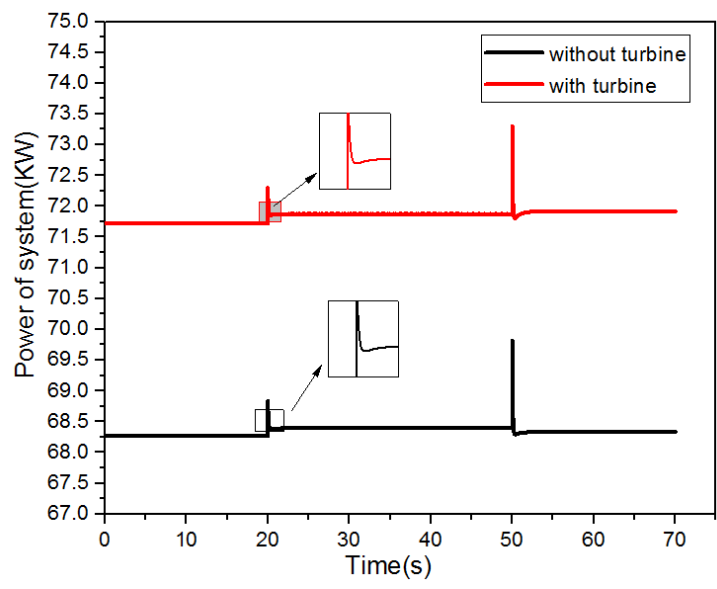

Fig. 8. System power contrast(with or without energy recovery turbine)

When the load current was changing, by controlling the voltage of the motor, the air flow rate of the compressor was kept stable, which would lead to the increase of parasitic power consumption (shown in Fig. $\left.{ }^{\circ} 6\right)$ and decrease the efficiency of the system. Parasitic power consumption accounted for about $1 / 5$ of the PEMFC power during 0-50s periods. During the 50-70s periods, it accounted for about $1 / 4$ of the PEMFC power, which had good consistency. As can be seen from Fig. ${ }^{\circ}$, with the increase of compressor pressure ratio, the power of recovery was increasing, because the pressure energy of exhaust gas was increasing. From Fig. ${ }^{\circ}$, it can be seen that the power of the system can be increased by adding the turbine structure to recover the exhaust gas energy. The power done by the exhaust gas on turbine accounted for about $5 \%$ of the power of the system and $18 \%$ of the parasitic power consumption. This is of great significance to the design of PEMFC system.

\section{Summary}

Based on air supply model of PEMFC, a mathematical model of exhaust gas recovery system was established to improve system power. In the model, the mass flow was controlled by controlling air excess ratio (about 2) to optimize the system power. Then in order to convert the work done by the exhaust gas on the turbine into other forms of energy, this paper combined the turbocharger with an electric compressor in series named series supercharger composite supercharging system. The simulation model of the series supercharger supercharging system was first established by Simulink software in this paper. Conclusions drawn out from a series of calculated results are as follows:

Exhaust gas recovery system can obviously improve the power of system. The higher the pressure energy of exhaust gas, the more power can be recovered.

The series supercharger supercharging system can obviously reduce the parasitic power consumption of the compressor and improve the power of the system, which has great advantages. 


\section{References}

1. Cunningham JM, Hoffman MA, The implications of using an expander (turbine) in an air system of a PEM fuel cell engine. J. Sci.53(2000)

2. Lanz, A, Heffel. J, Messer, C, Hydrogen fuel cell engines and related technologies, third ed. Palm desert: college of the desert, (2001).

3. Pukrushpan JT, Stefanopoulou AG, Peng H. Control of fuel cell breathing. J. Ei. 24(2004)

4. Pukrushpan JT, Peng $\mathrm{H}$ and Stefanopoulou AG. Control-oriented Modeling and Analysis for Automotive Fuel Cell Systems. J. Sci. 126(2004)

5. Ardalan V, Ilya K, and Anna S. Current Management in a Hybrid Fuel Cell Power System: A Model-Predictive Control Approach. J. Sci. 15(2007)
6. Kim DK, Seo JH, Kim S, et al. Efficiency improvement of a PEMFC system by applying a turbocharger. J. Sci. 39(2014)

7. Pucheng $\mathrm{P}, \mathrm{Wu} \mathrm{Y}$, Ping L. Numerical prediction on an automotive fuel cell driving system. J. Sci. 31(2006)

8. EG\&G Services Parsons Inc, Fuel cell handbook. fifth ed. Morgantown, West Virginia, (2000).

9. Amphlett, J. C. Mann, R. F. Peppley B. A. Roberge, P. R. Rodrigues, A model predicting transient responses of proton exchange membrane fuel cells. J. Sci. 61(1996).

10. Larminie, James. Rand, David A. J, Dicks, Andrew L. Fuel Cell Systems Explained, third ed., Wiley, England, (2018).

11. Larminie, James, Rand, David A J , Dicks, Andrew L. Fuel Cell Systems Explained, second ed., Wiley, England, (2003). 